\title{
Döküm Fabrikasında Günlük Üretim Verileri ile İşgücü Verimliliğinin Kontrolü
}

\author{
Burak OZTURK ${ }^{1 *}$,̇rem DUZDAR ARGUN², Özkan KUCUK ${ }^{3}$, Hasan OKTEM $^{4}$ \\ ${ }^{1}$ Asst. Prof., Bilecik Seyh Edebali University, Faculty of Engineering, Department of Metallurgical and \\ Materials Engineering, Orcid: 0000-0002-1018-6545 \\ ${ }^{2}$ Asst. Prof., Düzce University, Faculty of Engineering, Department of Industrial Engineering, \\ Orcid: 0000-0002-7642-8121 \\ ${ }^{3}$ Prof. Dr., Seyh Edebali University, Faculty of Engineering, Department of Metallurgical and Materials \\ Engineering, Orcid: 0000-0002-4337-4454 \\ ${ }^{4}$ Assoc. Prof. Dr., Kocaeli University, Hereke Vocational High School, Department of Machinery and Metal \\ Technologies, Orcid: 0000-0003-2526-8364
}

Geliş Tarihi/Received: 22.10.2018

Kabul Tarihi/Accepted: 04.12.2018
Doi: dx.doi.org/10.31200/makuubd.473360

Araştırma Makalesi/Research Article

\section{ÖZET}

$\mathrm{Bu}$ çalışmada, orta ölçekli bir boru elemanları döküm fabrikasına ait atölyelerde günlük üretim istatistikleri ile işgücü verimliliğinin ölçülmesi amacıyla geliştirilen bir analizinin tasarımı ve uygulaması ortaya konulmaktadır. Fabrikada bulunan değişik atölyelerde yapılan birbirinden farklı ve zor işler ile mamul ürünler ve operatörleri göz önünde bulundurularak “Dökümhane ve İmalathane Günlük Kayıt Formu” tasarlanmıştır. Analizin tasarımı ve geliştirilmesi İçin; boru elemanları döküm fabrikasında üretilen ürünler ve üretim süreçleri (Proses) incelenmiş, sistemin tasarımı için gerekli bilgiler elde edilmiştir. $\mathrm{Bu}$ amaçla; ürünlerin adı ürün ağırlık parametreleri, yolluk ağırlığı, salkım ağırlığı, salkımdaki ürün adedi, adet/süre parametreleri belirlenerek ve standartlaştırılarak Excel ortamında elektronik bir kütük sayfası oluşturulmuştur. Günlük üretim ve üretken/kayıp sürelerin elde edilmesini sağlayan günlük kayıt formundan yararlanılmıştır. Söz konusu günlük kayıt formu atölyeler bazında hem tablo hem form görünümündedir. Kullanım kolaylığı açısından, günlük kayıt formu ile aynı ara yüze sahip bir Excel kitabı ortamında oluşturulmuştur. Elde edilen verilerden günlük ve aylık üretim istatistikleri ile verimlilik oranlarını hesaplayan ve raporlayan bir kısa yol oluşturulmuştur. Böylece, bu program yardımıyla istenilen sonuca ulaşılmıştır. Fiziksel verimliliğe ilişkin kullanılan toplam maden miktarı, yolluk ağırlıkları ile mamul ağırlıkları, ürün miktarı, hatalı ürün miktarı ve oranları, işgücü verimliliğine ilişkin

* Sorumlu yazar/Corresponding author

E-mail/e-ileti: burak.ozturk@ bilecik.edu.tr 
günlük ve aylık oranlar ve verimliliği olumsuz yönde etkileyen faktörler gözlemlenebilir hale getirilmiştir.

Anahtar kelimeler: Zaman Etüdü, Üretim Programlama, Verimlilik, Dökümhane Üretim Programları.

\title{
Design and Application of Daily Production Data and Workforce Productivity Model in Casting Factory
}

\begin{abstract}
In this study, the design and application of a model developed for the measurement of labor productivity with daily production statistics are presented in the workshops of a medium sized fittings casting. "Foundry and Manufacturing Daily Registration Form" is designed by considering the different products and operators of different and hard work in different workshops in the factory. Design and Development of Models; the products and production processes (processes) of the fittings casting plant were examined and the necessary information for the design of the system was obtained. Therefore; product name, product weight parameters, runner weight, bunch weight, batch product name, number / time parameters have been determined and standardized and an electronic page has been created in Excel environment. It is used in the "Daily Registration Form" design which enables daily production and productive / loss times. The daily record form is in the form of a table and a form on the basis of workshops. From the point of view of ease of use, a study has been developed that is designed in an Excel book environment with the same interface as the daily registration form, and calculates and reports daily and monthly production statistics and productivity rates from the obtained data. Thus, by designing the model reached the conclusion he wanted the factory management; the total mineral amount used for physical efficiency, product weight with runners weights, product quantity, defective products quantity and rates, daily and compared monthly regard to labor productivity and made efficiency observable factors affecting negatively.
\end{abstract}

Keywords: Time Study, Production Programming, Productivity, Foundry Production Programs. 


\section{GíRiş̧}

Fittings boru bağlantı elemanları genellikle sıhhi tesisat ve doğalgaz sistemlerinde birden fazla borunun bir birine bağlanması işleminde kullanılmaktadır. Bu alanda üretim yapan endüstri kuruluşları incelendiğinde, ithal ürünler ile ekonomik olarak rekabet edemediği gözlemlenmiştir (Öztürk vd., 2017). Bununla birlikte bazı tasarım ve üretimde optimizasyon çalışmaları yapılmıştır (Küçük ve Öztürk, 2017: Kücük vd., 2017). Malzemelerinin mikro yapı özellikleri araştırılmış ve işlenebilirlik kabiliyetleri artırılmak istenmiştir (Öktem vd., 2017; Öztürk vd., 2016).

$\mathrm{Bu}$ çalışmalara ek olarak üretim kapasitesini artırmak için yeni bir derece sistemi geliştirilmiştir (Küçük vd., 2017_2). Bu çalışmalarda temel amaca endüstride yerli üretim yapan kuruluşlarda üretim kapasitesini artırma aynı zamanda ürün kalitesini artırmaktır.

$\mathrm{Bu}$ çalışmalardan farklı olarak fittings malzemelerin seri üretiminde önemli bir kısım ise işçi verimliliğini artırmak, minimum zamanda maksimum ürünü; hata miktarı ve işçi güvenliği dikkate alınarak üretmektir. Endüstride bu sorunları çözmek için birçok farklı alanda özel ERP (Kurumsal Kaynak Planlama) yazılımları kullanılmaktadır. Bu programlar kurumsal firmalarda kullanılmasına yönelik birçok çalışan ile birlikte uygulamamaktadır. Literatürde farklı alanlarda hazırlanmış uygulamalar ile farklı endüstriyel alanlarda üretim ve verimlilik kontrolü sağlanmıştır (Ozdamar, 2007; Kaygusuz, 2006; Gedik, 2007; Duran ve Çetindere, 2012).

Üretimin kontrolünde, değişkenlik ve gerçekleşmenin belirlenmesinde en önemli araç istatistiksel kalite kontrol diyagramlarıdır. $\mathrm{Bu}$ grafikleri kullanmayan bir yonga levha fabrikasında istatistiksel kalite kontrol grafikleri kullanılarak surecin kontrol altında olup olmadığı araştırılmıştır (Ozdamar, 2007). Excel programı kullanılarak üretim veya satın alma kararının verilmesi ile ilgili olarak klasik maliyet analizi ve kısıtlar teorisine göre karşılaştırmalı olarak incelenmiştir (Kaygusuz, 2006). Orman ürünleri sanayi MDF üretimi kalite kontrol diyagramları yardımıyla incelenmiştir (Gedik, 2007). Konfeksiyon sanayinde üretilen elbise modeline ait hata analizleri ve bu hataların çözümlenmesi istatistiksel proses kontrol teknikleri araştırılmıştır /Duran ve Çetindere, 2012). Dikiş hatalarının "İstatistiksel Proses Kontrol (İPK) Yöntemleri” kullanılarak azaltılması incelenmiştir (Kayaalp ve Erdoğan, 2009). 
Bu farklı alanlarda yapılan araştırmalarda temel hedef ürün kalitesini artırmak aynı zamanda üretim maliyetlerini azaltmaktadır. Boru bağlantı elemanlarının üretimi içinde benzer bir araç olarak Excel yardımı ile döküm ve imalat süreçlerine özel yazılım geliştirilmek istenmektedir. Böylece maliyetleri yüksek ve kullanılması için nitelikli eleman gerektiren programlar yerine ihtiyaca yönelik bir uygulama hazırlanacaktır. Üretim kalitesi artırılırken maliyetleri düşürülmüş nitelikli ürün üretimi ile fittings sanayinde ithal ürünler ile rekabet gücü artırılabilecektir. Ayrıca farklı endüstriyel alanlar için örnek bir uygulama oluşturulabilecektir.

\section{MATERYAL VE METOD}

İş gücü verimliliğinin belirlenmesi için tüm üretim proseslerinin ilk olarak belirlenmesi gereklidir. Bununla birlikte hatalı ürün, çalışma verimliliği ve ham madde kullanımı gibi verilerin kayıt altına alınması gereklidir. Sırası ile tüm basamaklar çeşitli ana başlıklar altında açıklanmıştır.

\section{1. Üretim Basamaklarının Belirlenmesi}

Araştırmaya konu fittings fabrikasında, operatörlerce doldurulan "Günlük Zaman Çizelgesi” verileri değerlendirme yapılması yönünden yetersiz bulunduğundan günlük üretim istatistiklerine ilişkin; maden miktarı, yolluk ağırlıkları, mamul ağırlıkları, ürün miktarı, hatalı ürün miktarı ve oranları ile günlük ve aylık işgücü verimlilik oranlarının belirlenmesi ve raporlanması için bir model tasarımı amaçlanmıştır. Fabrikada bulunan değişik atölyeler ve operatörleri göz önünde bulundurularak "Günlük Kayıt Formu” tasarlanmıştır. Kullanım kolaylığı açısından, günlük kayıt formu ile aynı ara yüze sahip bir Excel kitabı tasarlanarak, elde edilen verilerden günlük ve aylık üretim istatistikleri ile verimlilik oranlarını hesaplayan ve raporlayan pratik bir çalışma yapılmıştır.

Söz konusu günlük kayıt formu atölyeler bazında hem tablo hem form görünümündedir.

Üretim faaliyetleri ve performansı izleme, ölçme ve analize tabi tutabilmek için, istatistik olarak değerlendirilebilen ve raporlanabilen özellikteki veri toplama noktaları (üretim prosesleri) gözlemlenmiştir.

Boru elemanları (Fittings) döküm fabrikasında ana üretim süreçleri (Proses) incelenmiştir. Bunlar; 
- Modelleme prosesi

- Maça hazırlama prosesi

- Döküm kumu hazırlama prosesi

- Sfero döküm prosesi

- Isıl işlem prosesi (Temperleme)

- Taşlama prosesi

- Kumlama prosesi

- Talaşlı imalat prosesi

- Depolama prosesi

- Kaplama/Galveniz prosesi

Araştırmaya başlamadan önce model tasarımına katkı sağlaması amacıyla daha önce yürütülen ölçme ve iyileştirme faaliyetleri incelenmiştir. Şu şekildedir;

- Veri analiz prosesi

- Girdi kontrolü prosesi

- Son kontrol prosesi

- Müşteri şikayetleri ve memnuniyeti prosesi

- İç tetkik prosesi

- Düzeltici önleyici kontrol prosesi

- Uygun olmayan ürün prosesi

- Model revizyon prosesi prosesi

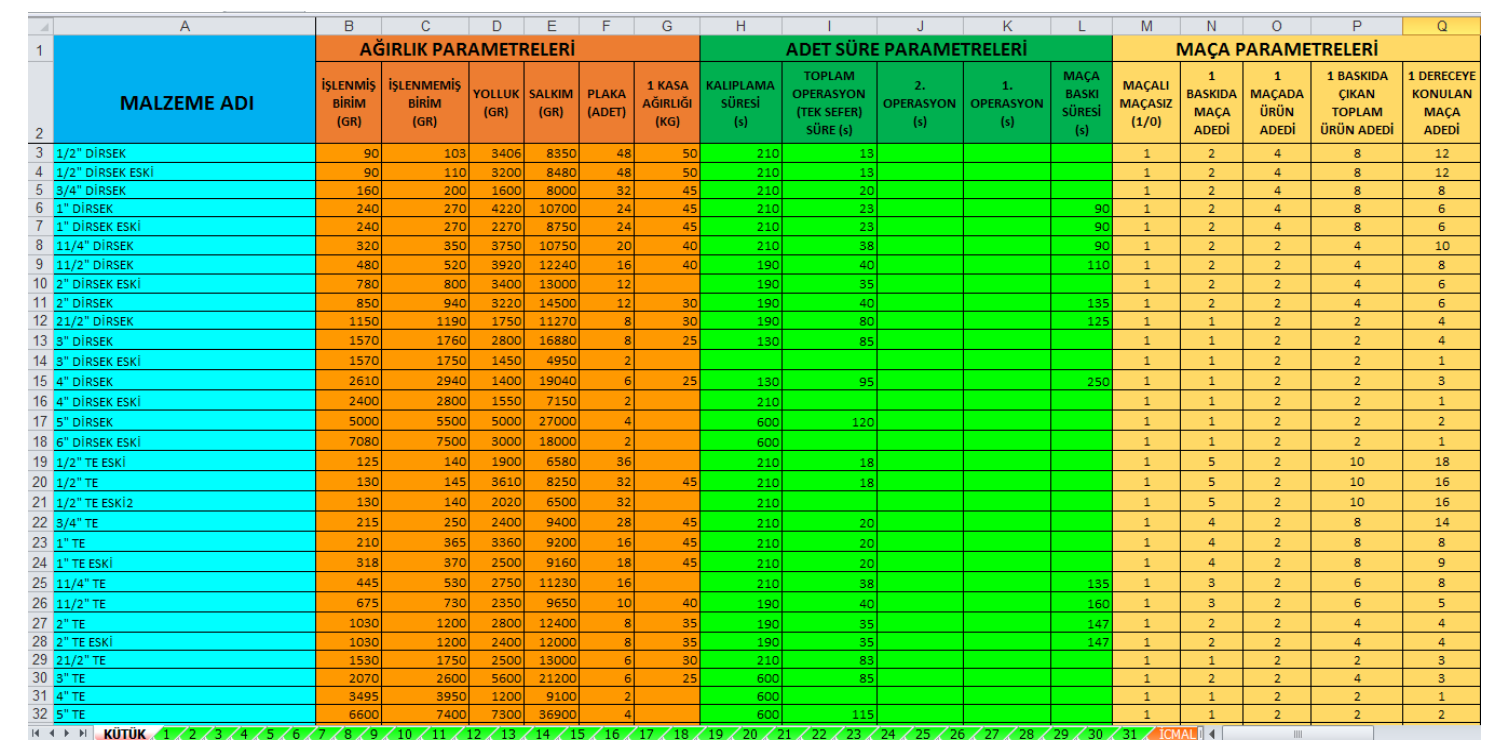

Şekil 1. Kütük sayfası ve parametreler 
Modelin tasarımı için gerekli bilgiler elde edilmiştir. $\mathrm{Bu}$ amaçla; Ürünlerin adı (Karmaşık bir isimlendirme sistemi bulunmaktadır). Ürün ağırlık parametreleri (işlenmiş ve işlenmemiş ağırlığı, yolluk ağırlığı, salkım ağırlığı, salkımdaki ürün adedi, kasa ağırlığı). Adet/süre parametreleri (Dökümhane derece kalıplama süreleri, talaşlı imalathane imalat süreleri, maça baskı süreleri).

Maça parametreleri (Ürünün maçalı olup olmadığı, 1 baskıda maça adedi, 1 maçada ürün adedi ve bir baskıda çıkan toplam ürün adedi, 1 derece kalıplamada kullanılan maça adedi) belirlenerek ve standartlaştırılarak Excel ortamında elektronik bir kütük (veritabanı) sayfası oluşturulmuştur.

Eski tarihlerde yapılan ölçümler, model yenileme ve geliştirmeleri nedeniyle yeni ölçümlerle güncellenmiş, ağırlık ve süre kaydı bulunmayan ürünler için yeni ölçümler yapılmıştır. Dökümhane atölyesinde yapılan çalışmalar ve üretim süreçleri incelenmiştir (Şekil 2.). Atölyenin performansını ölçmek için kullanabilecek ölçüt olarak sadece “derece/kalıplama” prosesi için standart zaman ölçümü dolayısıyla verimlilik ölçümü imkanı bulunmaktadır. Diğer yapılan işler müteferrik işler olarak görülmekte olup, verimlilik ölçümü yapmaya yönelik kategorik bir değerlendirmede bulunulmamıştır. Ancak, ocak sayısı, kum karıştırıcı sayısı ve ısıl firın sayısı nominal olarak değerlendirilmektedir. Fakat bu göstergeler de sürekli veri akışı sağladığından yorumlanabilir veri niteliğindedir.
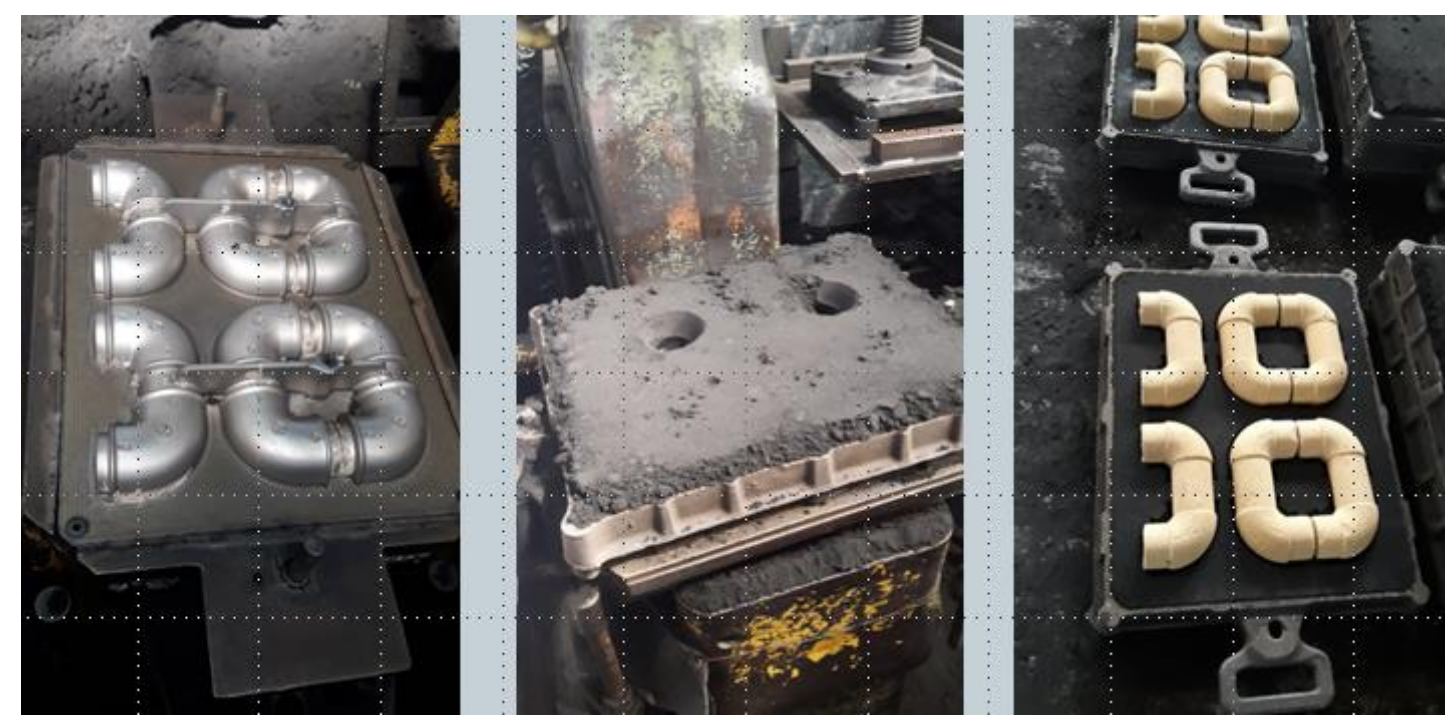

Şekil 2. Derece kalıplama (maçalı ürün)

Dökümhanede kalıplanan ve isıl fırında işlem (Temperleme/Menevişleme) gören malzemeler, çapakları alınmak üzere Taşlama Atölyesinden geçirilir. Bilahare Taşlanan 
(çapakları alınan) yarı mamuller, kumlama makinesinde temizleme ve parlatma ameliyesine tabi tutulur. Taşlama ve kumlama atölyesi, dökümhane ile talaşlı imalathane atölyeleri arasında köprü görevi görmektedir. Pratikte tartma imkanı olmadığı için ne kadar malzemeye taşlama ve kumlama yapıldığını ölçebilmek amacıyla, kasa sayımı ile yaklaşık olarak takip yapılmaktadır. Bunun için her malzemenin bir kasa ağırlığı ölçülerek veri tabanına ağırlık parametresi olarak işlenmiştir. Esasen döküm fabrikasında üretim süreci modelleme prosesi ile başlamaktadır. Bilahare geliştirilen modellere göre maça hazırlama prosesi yapılmaktadır. Maçahanede maça kumu, reçine ve serter karışımına kalıpta presleme ve pişirme işlemi uygulanmaktadır.

Malzemeleri maçalı olup olmadıklarına göre kategorize edebilmek için, maçalı malzemeler "1" , maçasız malzemeler "0" olarak kodlanmıştır. Araştırmaya başlamadan önce maçalı malzemeler ile ilgili veriler kayıtlı olmadığından, öncelikle maça veri tabanı parametreleri kayıt altına alınmaya başlanılmıştır. Sfero döküm parçalarının talaşlı imalat prosesinde; Havşa açma, Çapak temizleme, Uygun tezgahta diş çekme, Eksen ve mastar kontrolü vb. işlemleri gerçekleştirilmekte ve işlenen ürünler depoya sevk edilmektedir (Şekil $3)$.

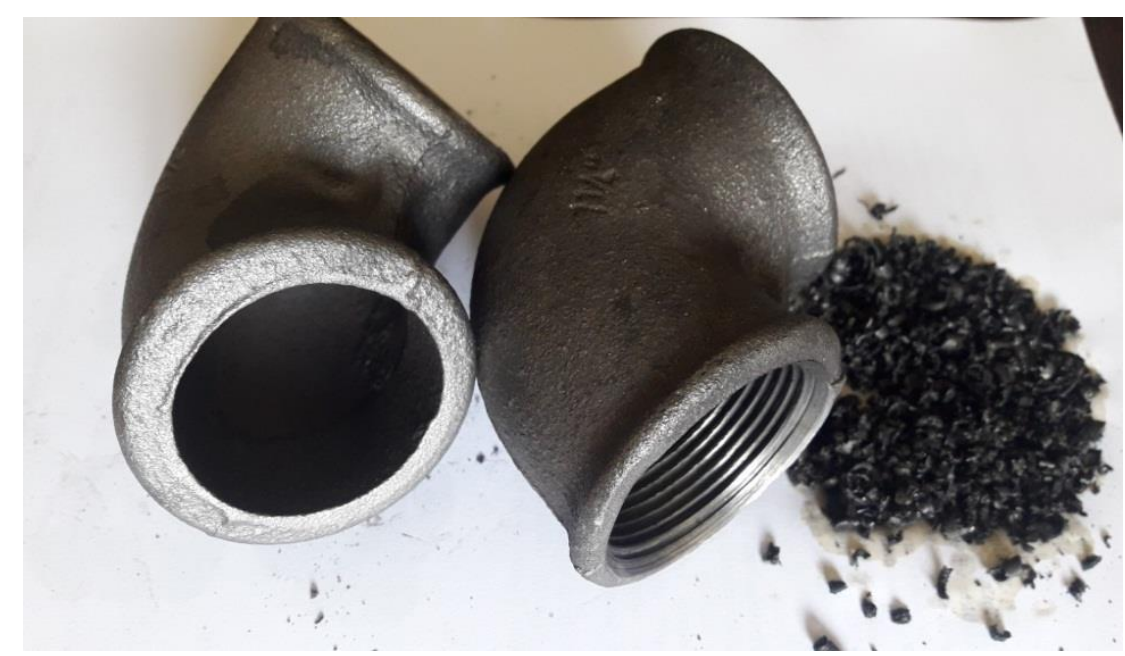

Şekil 3. Talaşıı imalat öncesi ve sonrası dirsek ile talaş resmi

\subsection{Hatalı Ürün Analizi}

Uygunsuzlukların sebebinin araştırılması, potansiyel risklerin ortaya çıkarılması ve gerekli önleyici ve düzeltici faaliyetlerin başlatılması için ürün ve proses performansının ölçülmesinde ve değerlendirilmesinde hatalı ürün istatistikleri kullanılmaktadır. Üretim sırasında ve mamulde tespit edilen uygunsuzluklar Günlük Kayıt Formu'na düzenli olarak 
kaydedilir ve Üretim Sorumlusu tarafından düzeltici ve önleyici faaliyetler hemen başlatılır (Şekil 4.)

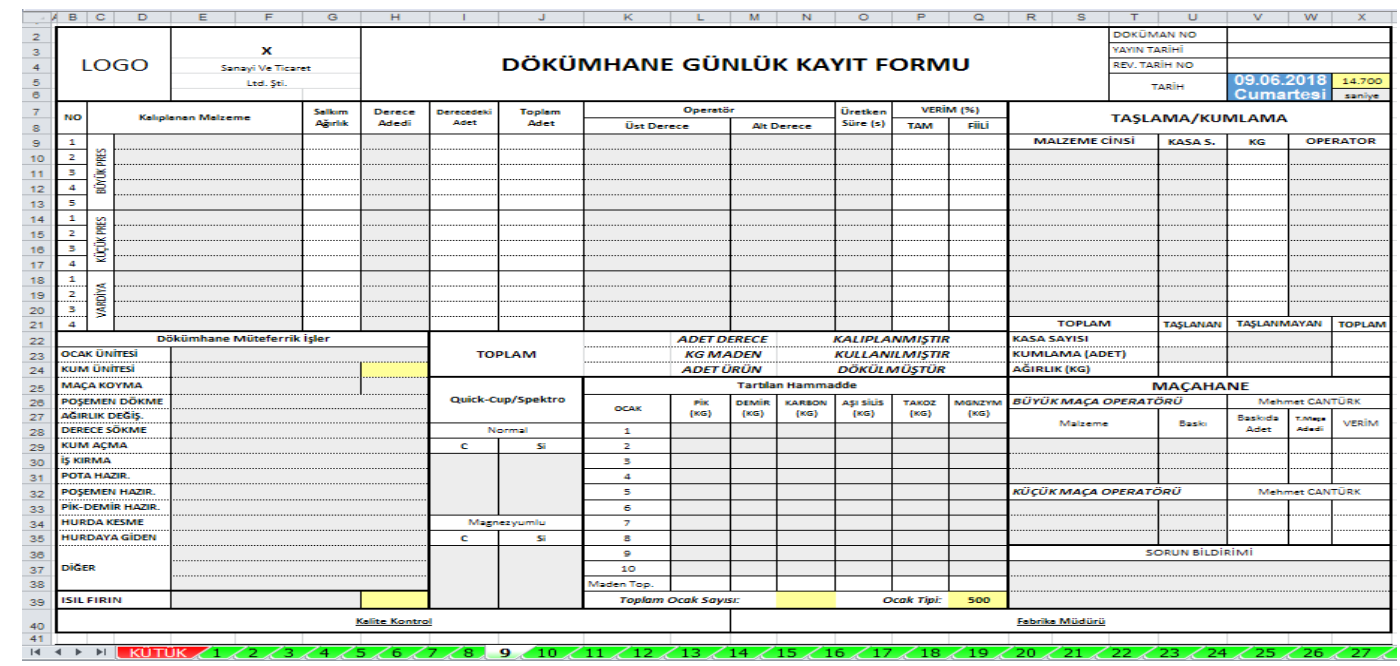

Şekil 4. Tasarım; günlük kayıt formu (1. sayfa)

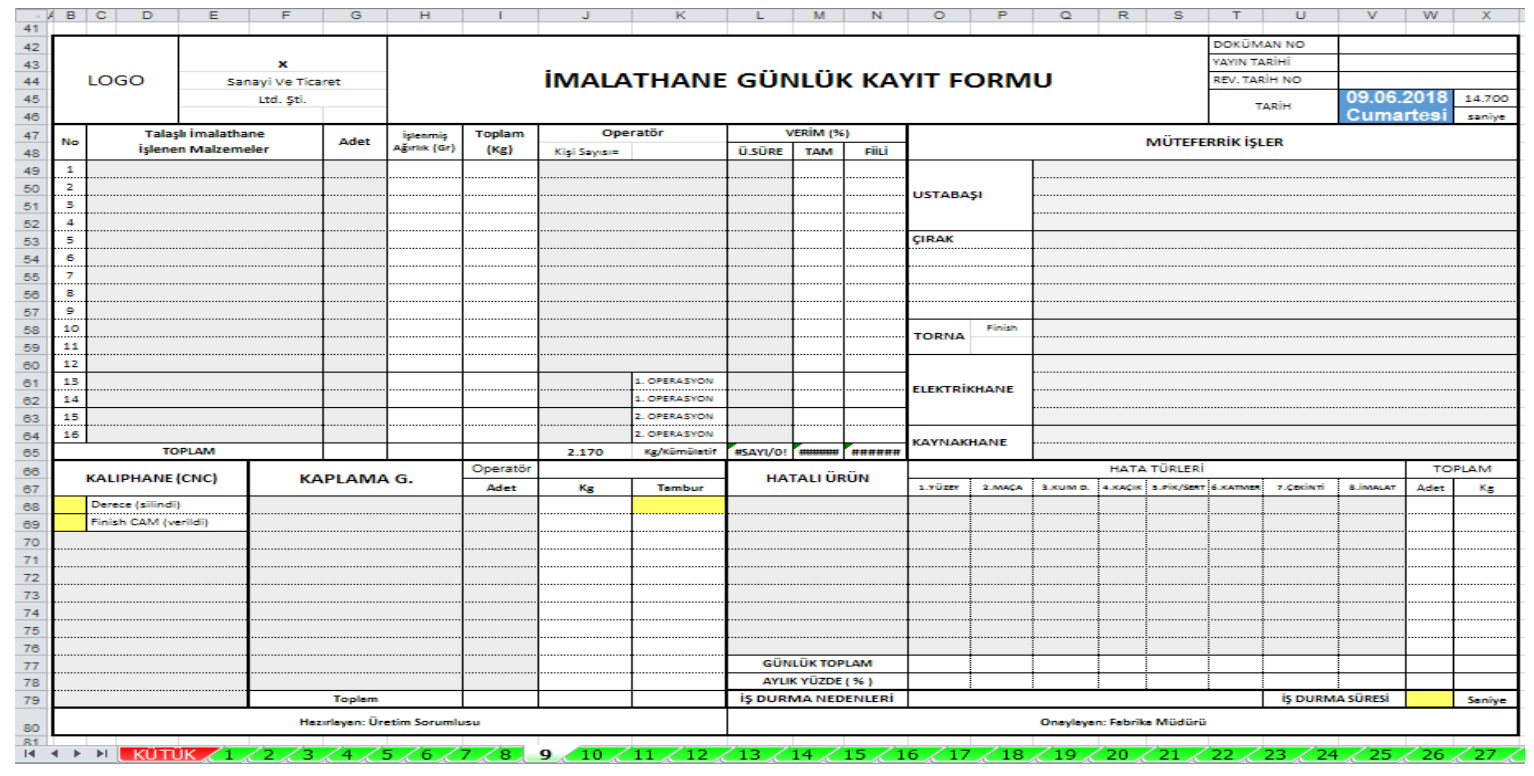

Şekil 5. Tasarım; günlük kayıt formu (2. sayfa)

\subsection{Günlük Kayıt Formunun Doldurulması ve Formüller}

Günlük yapılan veri girişleri sonucunda, günlük kayıt formu aynı zamanda günlük üretim faaliyet raporu niteliğindedir. Söz konusu verilerin aylık raporlara dönüştürülmesi amacıyla, aynı excel kitabında her atölye bazında açılan sayfalarda günlük veriler çarşaf liste haline getirilmek suretiyle aylık icmaller toplanmaktadır. Söz konusu icmal sayfalarında her bir işgünü alt alta yansıtılarak bir aylık görünüm oluşturulmuştur. 
Böylece günlük üretim istatistikleri toplanabilir ve hesaplanabilir hale getirilmektedir. Bilahare, yine aynı Excel kitabında her bir atölyenin aylık icmal sayfasında oluşturulan verilerin yansıtıldığı bir rapor sayfası oluşturularak döngü tamamlanmaktadır.

\subsubsection{Dökümhane günlük kayıt formunun doldurulması ve işleyişi}

Kısımlar (Büyük Pres, Küçük Pres) tarafından kalıplanan malzeme adı yazılınca (Yazım hatası yapılmaması gerekiyor), aşağıdaki formül ile kütük sayfasından salkım ağırlık parametresini salkım ağırlık sütununda otomatik olarak gösterir (Eş. 1).

$=\operatorname{ETOPLA}(K U ̈ T U ̈ K ! A: A ; D 9 ; K U ̈ T U ̈ K ! E: E)$

(Eşitlik 1.)

Salkım ağırlık miktarı ile derece adedinin çarpımı ile dökülen maden miktarı bulunur (Eş. 2).

MADEN MíKTARI = Salkım Ağırlık *Kalıplanan Derece Adedi

(Eşitlik 2.)

Kalıplanan derece adedi ile derecedeki adet miktarı çarpımından toplam kalıplanan malzeme adedi bulunur (Eş. 3).

TOPLAM ÜRETİM ADEDİ = Derecedeki Adet $*$ Kalıplanan Derece Sayısı （Eşitlik 3.)

\subsubsection{Taşlama atölyesi günlük kayıt formunun doldurulması ve işleyişi}

Malzeme adı ve kasa sayısı kaydı yapıldığında taşlanan malzeme miktarı bulunmaktadır (Eş. 4).

=ETOPLA(KÜTÜK!A:A;R10;KÜTÜK!G:G)*U10

(Eşitlik 4.)

Diğer taraftan, taşlama işleminden sonra kumlama makinesinde bir seferde yaklaşık $180 \mathrm{~kg}$ (Maksimum $200 \mathrm{~kg}$ ) malzeme kumlama yapılmaktadır. Kumlama adedi de nominal olarak kaydedilmekte olup, sürekli veri akışı sağladığından yorumlanabilir veri niteliğindedir.

\subsubsection{Maçahane atölyesi günlük kayıt formunun doldurulması ve işleyişi}

Döküm işlemi öncesi maça gerektiren ürünler için sıcak maça üretimi yapılmaktadır. Şekil 6'da maça üretimi için gerekli parametreler ve programdaki gösterim yerleri yer almaktadır. 


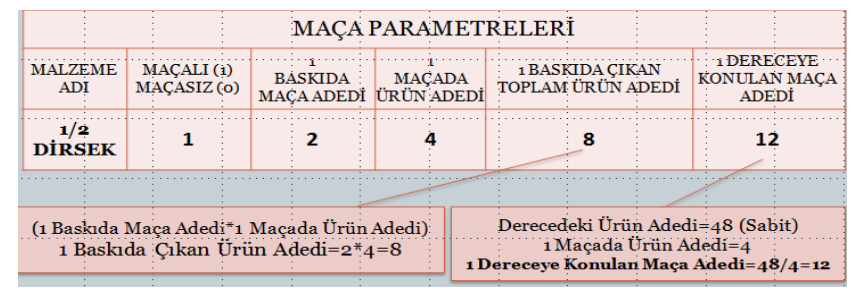

Şekil 6. Maça üretim parametreleri

\subsubsection{Talaşlı imalathane atölyesi günlük kayıt formunun doldurulması ve işleyişi}

İşlenen malzeme adı yazılınca işlenmiş ağırlık sütununda söz konusu malzemenin işlenmiş ağırlık miktarı otomatik olarak gösterilir (Eş. 5).

$$
\text { =ETOPLA(KÜTÜK!A:A;C49;KÜTÜK!B:B) }
$$

İşlenmiş birim ağırlık miktarı ile işlenmiş malzeme adedinin çarpımı ile toplam imal edilen işlenmiş ağırlı miktarı bulunur. Böylece ağırlık bazında imalat daha anlamlı görüldüğünden, talaşlı imalathanede günlük imalat miktarı ağırlık (Kg) yönünden hesaplanmakta ve takip edilmektedir. Verimlilik ölçümü için, aşağıdaki "İşgücü Adam-Saat Girdisi» modeli esas alınmaktadır. Bu modele göre 2 ölçüm yapılmaktadır:

1. Tam zamanlı verimlilik= Standart Adam Saatler/Toplam Adam Saat

2. Kısmi Zamanlı Verimlilik=Etkili Adam Saatler/Adam Saat Girdisi

\subsection{5. İşgücü verimlilik hesaplamaları}

Hesaplamaya esas olmak üzere günler ve mesai süreleri form üzerinde formülleştirilerek gösterilmektedir (Şekil 7.), (Eş. 6).

$$
=(E \breve{G} E R(V 6=\text { "Pazartesi"; 29400; Ĕ̆ ER(V6 = "Sall"; 29400; ĔĞER(V6 = }
$$

"Çarşamba"; 29400; ĔĞER(V6 = "Perşembe"; 29400; ĔĞER(V6 = "Cuma"; 29400; EĞER(V6 =

"Cumartesi"; 14700; ĔGER(V6 = "Pazar"; 0)))))))) -W79

(Eşitlik 6.)

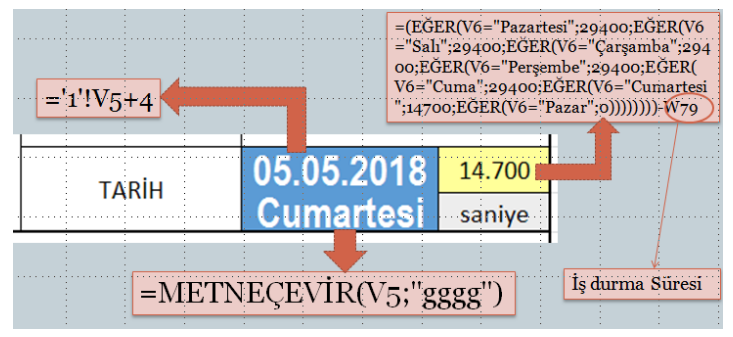

Şekil 7. Verimlilik hesaplama parametreleri 


\subsubsection{Tam zamanlı standart verimlilik (Tam) :}

İlk olarak, tam mesai süresine kıyasla standart üretken süre verimliliği ölçülmektedir (Eş. 7).

$$
\operatorname{Verimlilik}(\text { Tam) }=\text { Standart Adam Saatler }(\text { LS }) / \text { Toplam Adam Saat (LR) }
$$

(Eşitlik 7.)

$\mathrm{Bu}$ ölçüm (Kullanılmayan süre +Kayıp süre +işçi verimliliği) etkisinden arındırılmış ve adet/süreye dayalı mutlak verimlilik ölçümüdür. Yani yapılan işin, robotik tam bir mesai ile kıyaslanmasıdır. Excel çalışma kitabında şu şekilde formüle edilmiştir (Eş. 8).

$=$ ETOPLA $(K U ̈ T U ̈ K ! A: A ; C 49 ; K U ̈ T U ̈ K ! I: I) * G 49 / \$ X \$ 5 * 100$

(Eşitlik 8.)

\subsubsection{Kısmi zamanlı standart verimlilik:}

Zaman çizelgesinde işin başlama ve bitiş tarihleri doğrultusunda işe ayrılan fiili üretken sürenin verimliliği ölçülmektedir (Eş. 9).

Verimlilik $($ Kısmi $)=$ Etkili Adam Saatler $\left(\mathrm{L}_{\mathrm{E}}\right) /$ Adam Saat Girdisi $\left(\mathrm{L}_{\mathrm{R}}\right)$

(Eşitlik 9.)

$\mathrm{Bu}$ ölçüm (Kullanılmayan süre +Kayıp süre) etkisinden arındırılmış ve adet/süreye dayalı mutlak verimlilik ölçümüdür. Excel çalışma kitabında şu şekilde formüle edilmiştir (Eş. 10).

ETOPLA(K ̈̈TÜK! A: A;C49; K ̈̈TÜK!I:I) * G49/L49*100

(Eşitlik 10.)

Tam ve kısmi zamanlı verimlilik kayıtlarından ve zaman çizelgesinde işin başlama ve bitiş tarihleri doğrultusunda işe ayrılan fiili üretken süre toplamlarından atölye verimliliği ölçülmekte ve gözlemlenmektedir (Şekil 8.).

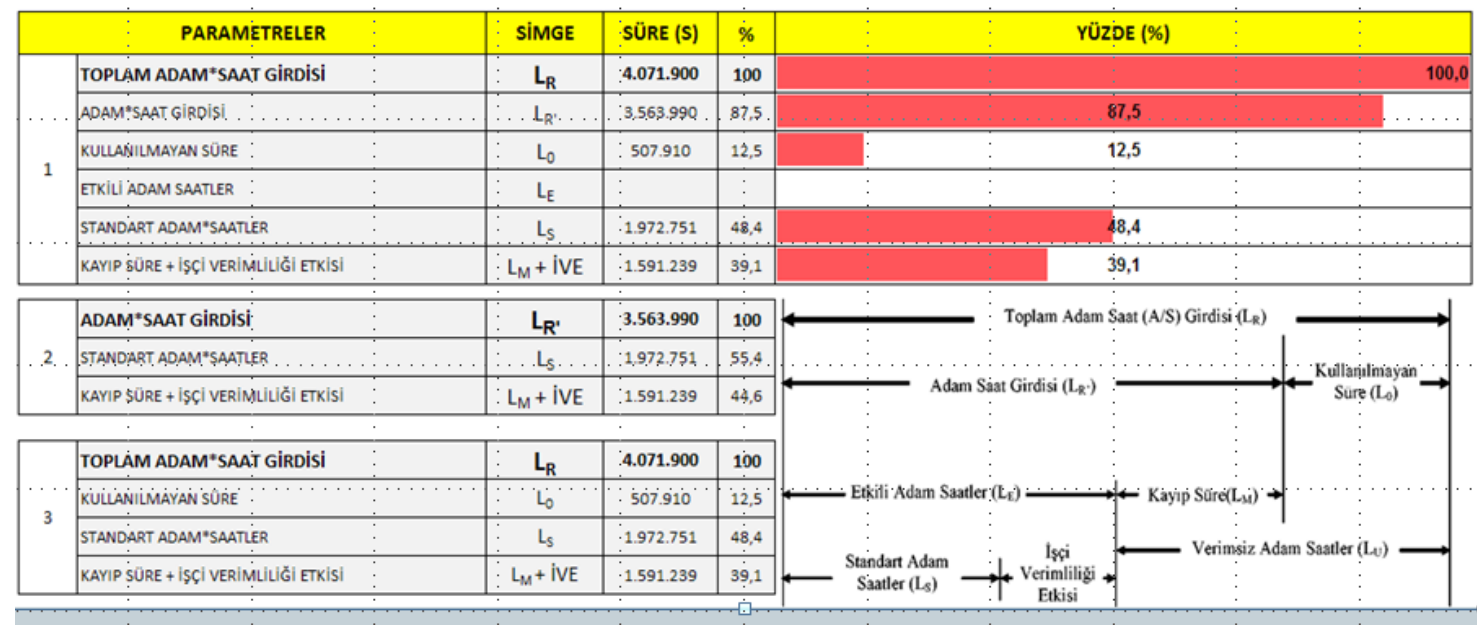

Şekil 8. İmalathane işgücü verimlilik yapısı 
Ozturk, B., Argun Duzdar, I., Kucuk, O. \& Oktem, H.

\section{SONUÇLARIN SAYISAL VERILERİ}

İstatistik tekniklerin her birinin uygulanması için öncelikle uygun veri toplanmasına ihtiyaç vardır. Verilerin toplanması sırasında objektif davranılmasına ve yanlı veri toplanmamasına özen gösterilmesi gerekmektedir.

Belirlenen amaca uygun değerlendirmelerin yapılabilmesine firsat verecek veriler, ilgili sorumluları tarafından, faaliyet sürecinde kullanılan formlardan toplanır. İş başlamadan önce operatörlere dağıtılan zaman çizelgeleri ile işin başlangıç ve bitiş zamanları, ürün-işlem sayısı tespit edilir. Çalışma saati bitiminde formun doldurulması tamamlanır ve ertesi gün formlar toplanarak veriler sisteme girilir. Böylece günlük kayıt formlarından hareketle istatistik yöntemler uygulanarak sonuçlar raporlanabilir hale gelmekte ve kayıtların dijital ortamda tutulması sağlanmaktadır. Söz konusu raporlar yönetimin gözden geçirme toplantılarında değerlendirilir. Operatörlere dağıtılan “Zaman Çizelgesi”nin “Günlük Kayıt Formu“na kaydedilmesiyle birlikte; Fiziksel verimlilik, Üretken süre toplamları ve işgücü verimlilikleri, ölçülmekte ve gözlemlenmekte olup, model ile hedeflenen amaca ulaşılmıştır (Tablo 1., Şekil 9.).

Tablo 1. Örnek verimlilik sonuçları

\begin{tabular}{|c|c|c|c|c|c|c|c|c|}
\hline \multirow{2}{*}{ Operatör } & \multicolumn{4}{|c|}{ Fiziksel Verimlilik } & \multirow{2}{*}{ Üretken } & \multicolumn{3}{c|}{ İsgücü Verimlilik (\%) } \\
& Adet & $\%$ & Kg & \% & Süre (s) & Tam & Fiili & Kümülatif \\
\hline Operatör-1 & 6.489 & 10 & 1.027 & 6 & 99.430 & 32 & 99 & 413 \\
\hline Operatör-2 & 21.144 & 31 & 6.816 & 39 & 749.760 & 74 & 70 & 2.011 \\
\hline Operatör-3 & 4.626 & 7 & 2.077 & 12 & 688.000 & 52 & 56 & 1.414 \\
\hline Operatör-4 & 18.230 & 27 & 2.552 & 15 & 741.600 & 59 & 56 & 1.598 \\
\hline Operatör-5 & 9.286 & 14 & 3.186 & 18 & 595.800 & 43 & 46 & 1.028 \\
\hline Operatör-6 & 3.760 & 6 & 908 & 5 & 368.100 & 42 & 47 & 679 \\
\hline Operatör-7 & 3.902 & 6 & 872 & 5 & 295.800 & 30 & 41 & 449 \\
\hline Operatör-8 & 200 & 0 & 31 & 0 & 25.500 & 45 & 49 & 45 \\
\hline TOPLAM & 67.637 & 100 & 17.467 & 100 & 3.563 .990 & 47,2 & 58,1 & 7.636 \\
\hline
\end{tabular}

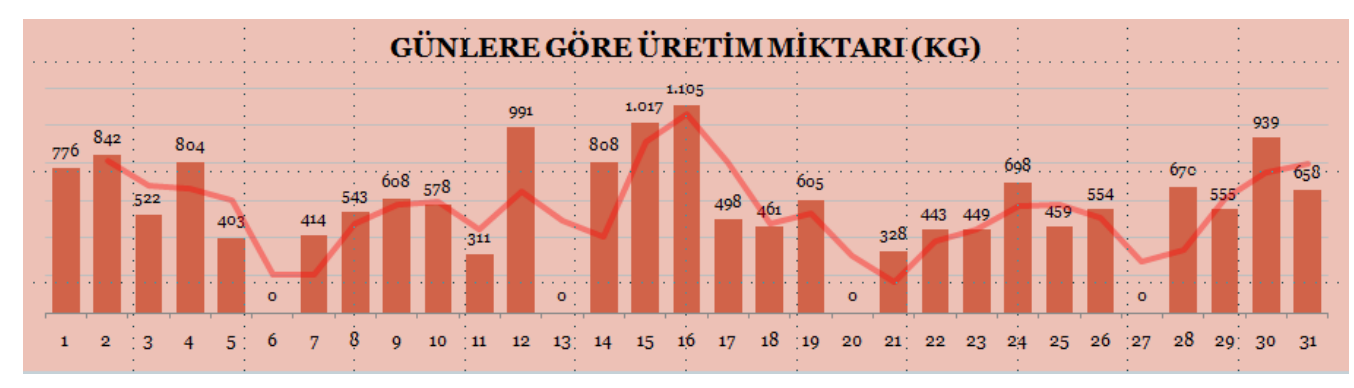

Şekil 9. İmalathane işgücü verimlilik yapısı 
Dökümhanede kalıplamanın yapıldığı pres tipine göre harcanan ham madde ve üretimi yapılan tüm ürün tipleri bu geliştirilen ara yüz yardımı ile kontrol edilebilmektedir (Tablo 2.). Üretimi yapılan mamullerin bütün özellikleri tablo 2' de yer almaktadır.

Tablo 2. Dökümhane üretim verileri

\begin{tabular}{|c|c|c|c|c|c|c|}
\hline \multirow{2}{*}{ KISIMLAR } & \multirow{2}{*}{$\begin{array}{l}\text { KALIPLANAN } \\
\text { DERECE } \\
\text { SAYISI (Adet) }\end{array}$} & \multirow{2}{*}{$\begin{array}{c}\text { MADEN } \\
(\mathbf{K g})\end{array}$} & \multirow{2}{*}{$\begin{array}{l}\text { ÜRÜN } \\
\text { (Adet) }\end{array}$} & \multirow{2}{*}{$\begin{array}{l}\text { KALIPLAMA } \\
\text { SÜRESİ (S) }\end{array}$} & \multicolumn{2}{|c|}{$\begin{array}{c}\text { KALIPLAMA VERIM } \\
(\%)\end{array}$} \\
\hline & & & & & $\begin{array}{c}\text { TAM } \\
\text { ZAMANLI }\end{array}$ & $\begin{array}{l}\text { DİĞER } \\
\text { İŞLER }\end{array}$ \\
\hline $\begin{array}{c}\text { BÜYÜK } \\
\text { PRES }\end{array}$ & 2.256 & 23.404 & 42.036 & 397.870 & 68 & 32 \\
\hline $\begin{array}{l}\text { KÜÇÜK } \\
\text { PRES }\end{array}$ & 1.761 & 9.706 & 23.802 & 241.475 & 40 & 60 \\
\hline VARDIYA & 208 & 1.893 & 1.560 & 31.110 & 26 & 74 \\
\hline TOPLAM & 4.225 & 35.003 & 67.398 & 670.455 & & \\
\hline
\end{tabular}

Boru bağlantı elemanlarının seri üretimi yapılırken birçok farklı döküm hatası ortaya çıkabilmektedir. Bu döküm hataları imalat işleminde meydana gelen imalat hataları ile birlikte toplam sekiz farklı hata tipine neden olmaktadır. Bu oluşturulan program yardımıyla günlük, aylık ve yıllık olarak tüm döküm hataları gözlemlenebilmektedir (Tablo 3.). Ayrıca şekil 10 ’da gösterildiği üzere grafik haline getirilebilmektedir.

Tablo 3. Hatalı ürün istatistikleri

\begin{tabular}{|c|c|c|c|c|c|c|c|c|c|c|c|c|c|c|c|c|c|c|}
\hline \multirow{2}{*}{$\begin{array}{c}\text { HATALI } \\
\text { MALZEME ADI }\end{array}$} & \multicolumn{2}{|c|}{ 1.YÜZEY } & \multicolumn{2}{|c|}{ 2.MAÇA } & \multicolumn{2}{|c|}{ 3.KUM D. } & \multicolumn{2}{|c|}{ 4.KAÇIK } & \multicolumn{2}{|c|}{ 5.PİK/SERT } & \multicolumn{2}{|c|}{ 6.KATMER } & \multicolumn{2}{|c|}{ 7.ÇEKİNTİ } & \multicolumn{2}{|c|}{ 8.İMALAT } & \multicolumn{2}{|c|}{ TOPLAM } \\
\hline & Adet & $\mathrm{Kg}$ & Adet & $\mathrm{Kg}$ & Adet & $\mathrm{Kg}$ & Adet & $\mathrm{Kg}$ & Adet & $\mathrm{Kg}$ & Adet & $\mathrm{Kg}$ & Adet & $\mathrm{Kg}$ & Adet & $\mathrm{Kg}$ & Adet & $\mathrm{Kg}$ \\
\hline 3/4" DİRSEK & 15 & 3 & 0 & 0 & 10 & 2 & 97 & 19,4 & \begin{tabular}{|l|}
1350 \\
\end{tabular} & 270 & 306 & 61,2 & 0 & 0 & 2 & 0,4 & 1780 & 356 \\
\hline 1" DİRSEK & 65 & 17,6 & 0 & 0 & 24 & 6,48 & 104 & 28,1 & 388 & 104,76 & 41 & 11,07 & 1 & 0,3 & 0 & 0 & 623 & 168 \\
\hline $\begin{array}{l}\text { 11/4"+1"+1" } \\
\text { İNEGAL TE }\end{array}$ & 73 & 29 & 0 & 0 & 52 & 21 & 111 & 44 & 289 & 116 & 11 & 4 & 1 & 0 & 0 & 0 & 537 & 215 \\
\hline $\begin{array}{c}"+1 / 2 " \text { MANŞON } \\
\text { REDÜKSIYON }\end{array}$ & 110 & 19 & 0 & 0 & 50 & 9 & 241 & 42 & 32 & 6 & 34 & 6 & 13 & 2 & 16 & 3 & 496 & 87 \\
\hline $11 / 4^{\prime \prime} \mathrm{TE}$ & 34 & 18 & 0 & 0 & 127 & 67,31 & 59 & 31,3 & 7 & 3,71 & 39 & 20,67 & 3 & 1,6 & 6 & 3,2 & 275 & 146 \\
\hline
\end{tabular}




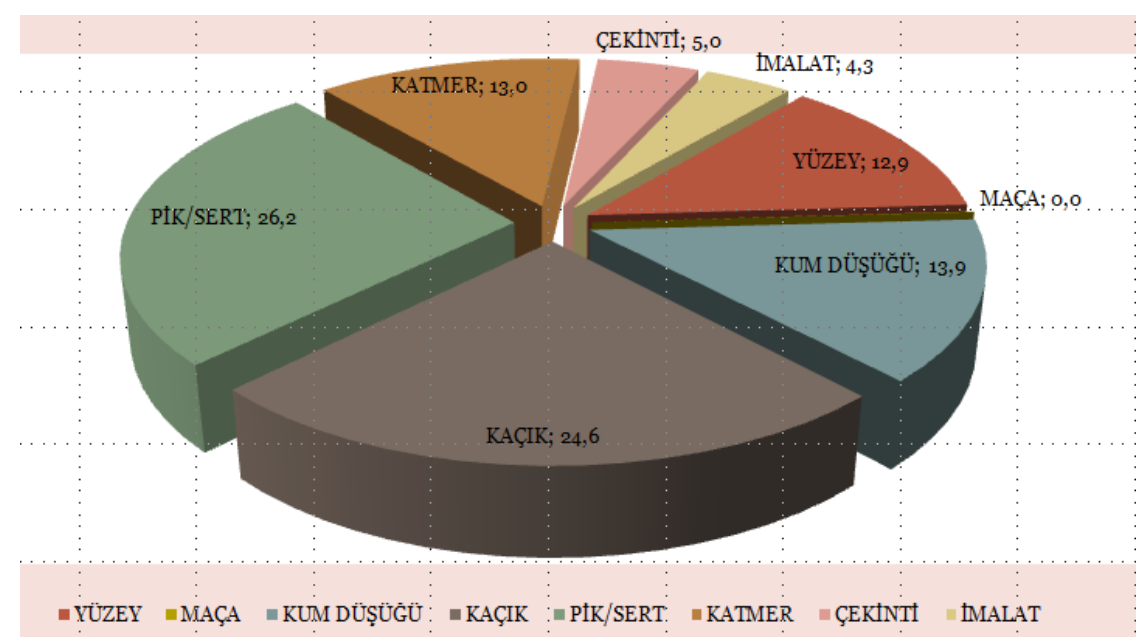

Şekil 10. Hatalı ürün dağılım grafiği

\section{TARTIŞMA}

Seri üretim boru bağlantı elemanlarının üretiminin yapıldığı orta ölçekli bir endüstriyel kuruşta üretim, kalite, kapasite, verimlilik, hammadde ve iş gücü Excel programı kullanılarak kontrolü sağlanmıştır. Lisans bedelleri orta ve küçük ölçekli endüstriyel kuruluşlar için çok yüksek olan ERP paket programları yerine daha uygun maliyetli işe ve kullanımı kolay kuruluşa adapte olabilir programların geliştirilmesi adına örnek bir uygulama olmuştur.

Dökümhane hata tipleri incelendiğinde küreselleşmemiş malzeme üretimi \%26,2 değer ile en yüksek hata oranını oluşturmaktadır. Bunu sırası ile kaçık ve kum düşüğü hataları izlemektedir. İmalat ve çekinti ise en düşük hata tipidir. Kaçık sorununu çözmek için model değişimi veya plaka deliklerinin kontrolü yapılması faaliyet olarak belirlenmiştir. Küreselleşme ve aşılayıcı kontrolü ile malzemenin pik sorununun önüne geçilebileceği düşünülmektedir.

$\mathrm{Bu}$ program yardımı ile talaşlı imalat biriminde iş verimliliği hesaplanmıştır. Fiili ortalama verimlilik \%58,1 ölçülürken $\% 47,2$ oranda çalışma süresi zamanında imalat gerçekleşmektedir. Verimlilik değerlerinin düşük olduğu gözlemlenmiştir. İş gücünde oluşan bu kayıp yerli endüstriyel kuruluşun ithal ürünler ile rekabet gücünü azaltmıştır.

\section{REFERENCES / KAYNAKLAR}

Duran, C. \& Çetindere, Ç. (2012). Konfeksiyon sanayiinde faaliyet gösteren bir işletmede istatistiksel proses kontrol teknikleri ile ürün hatalarının analiz edilmesi. Ç. Ü. Sosyal Bilimler Enstitüsü Dergisi, 21(2), $233-254$. 
Gedik, T. \& Akyüz, K.C. (2006). Mdf üretiminde kalite kontro diyagramları yardımıyla süreç kontrolü. İstanbul Üniversitesi Orman Fakültesi Dergisi, 75-91, 57-2.

Kayaalp, İ.D., \& Erdogan, M.Ç. (2009). Konfeksiyon işletmesinde dikiş hatalarının istatistiksel proses kontrol yöntemlerini kullanarak azaltılması. Tekstil ve Konfeksiyon, 169-174, 2.

Kaygusuz, S.Y. (2006). Üretim veya satın alma kararlarında kısıtlar teorisi ve ms excel office programının birlikte kullanılması. İktisadi ve İdari Bilimler Dergisi, 20, 159-177.

Küçük, Ö. Öztürk B., Altınbilek, Y.S. \& Elfarah, T. (2017). Şehir su şebekesinde; tesisat boru bağlantı elemanlarının akışkan analizine bağlı basınç dayanım analizinin yapılması. Kastamonu University Journal of Engineering and Science, 3(2), 32-43.

Küçük, Ö. Öztürk, B. Düzdar, İ. Varhan, S. \& Çetindağ H.A. (2017_2). Seri üretim boru bağlantı elemanlarının döküm işleminde optimizasyon, Politeknik, 20(3), 537-542.

Küçük, Ö. \& Öztürk, B. (2017). Development of design geometry of aluminum fittings for healthy and safety sanitary installations. Journal of Environmental Protectionand Ecology, 18(2), 776-787.

Ozdamar, H.İ. (2007). Orman ürunleri endüstrisinde istatistiksel kalite kontrol yonga levha üretiminde bir çalışma. Süleyman Demirel Üniversitesi Orman Fakültesi Dergisi, 1, 79-91.

Öktem, H. Öztürk, B. Akincioğlu, \& S. (2017). Investigation of energy consumption on thread machining of austempered ductile cast iron materials, 5th International Conference and Exhibition on Mechanical \& Aerospace Engineering, Doi: 10.4172/2168-9792-C1-01, October 02-04, 2017, Las Vegas, USA.

Öztürk, B. Küçük, Ö. Düzdar, İ. \& Altınbilek, Y.S. (2017). Exploring the economial reasons of the usage of unhealthy \& low resisting far-east products in the water pipe system, The Turkish Journal of Occupational / Environmental Medicine and Safety, Volume: The 2nd international Water and Health Congress, 0-8.

Öztürk, B. Öktem, H. Said, G. Çetindağ, H.A. \& Erzincanlı F. (2016). İnvestigation of cooling rate on hardness and microstructure in casting fittings materials, 2.International Symposium on Innovative Technologies in Engineering and Science, 1279. 